TRW No. 97248.000

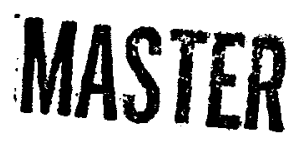

USE OF GEOTHERMAL HEAT

FOR SUGAR REFINING

IN IMPERIAL COUNTY

\title{
GEOTHERMAL TEST PLAN
}

FEBRUARY 1980

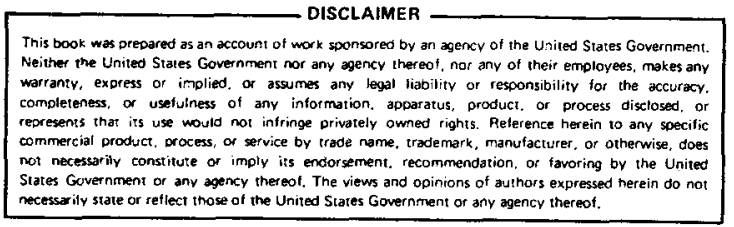

DOE Contract No. DE-AC 03/79 ET 27039

Prepared for :

\section{U. S. DEPARTMENT OF ENERGY}

\section{NOTICE}

PORTIONS OF THIS REPORT ARE ILLEGIBLE. It has been reproduced from the best avaliablo copy to permit the broadest possible avaif ability, 


\section{DISCLAIMER}

This report was prepared as an account of work sponsored by an agency of the United States Government. Neither the United States Government nor any agency Thereof, nor any of their employees, makes any warranty, express or implied, or assumes any legal liability or responsibility for the accuracy, completeness, or usefulness of any information, apparatus, product, or process disclosed, or represents that its use would not infringe privately owned rights. Reference herein to any specific commercial product, process, or service by trade name, trademark, manufacturer, or otherwise does not necessarily constitute or imply its endorsement, recommendation, or favoring by the United States Government or any agency thereof. The views and opinions of authors expressed herein do not necessarily state or reflect those of the United States Government or any agency thereof. 


\section{DISCLAIMER}

Portions of this document may be illegible in electronic image products. Images are produced from the best available original document. 


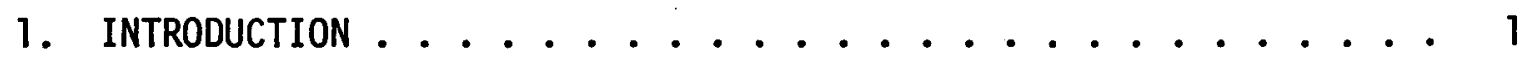

2. RESOURCE TESTING AND DATA GATHERING ........... 3

2.1 Production Well Drilling ............ 3

2.1 .1 Mud Logging ................ 3

2.1 .2 Geophysical Logging ............ 8

2.1.2.1 Alternatives in the Logging Program ... 9 9

2.1.2.2 Logging Program for the Injection Wel1 . . 11

2.1 .3 Drill Stem Testing ............ 12

2.1.3.1 Production Well Tests ......... 12

2.1.3.2 Injection Well DST ......... 13

2.1.4 Fluid Analysis ............... . . 14

2.2 Short Term Production Tests . . . . . . . . 15

2.3 Injection Well .................. 17

2.3.1 Mud Logging ................. . 17

2.3.2 Geophysical Logging ............ 17

2.3.3 Cores and Core Data ............ 18

2.4 Full Scale Production Tests . . . . . . . . . 18

2.4.1 Installation of Equipment ......... 19

2.4.2 Flow Tests ................... 19

2.4.3 Pressure/Temperature Testing ......... 22

\section{LIST OF FIGURES}

1. Schedule and Milestones for Resource and Injection Testing,

Holiy Sugar Project............... 2

2. Geothermal Data Log ............... 7

3. Wellhead Design ..................... 20

4. Production Well Test Loop . . . . . . . . . . . 21

5. Injection Well System ............... 22

TABLE

1. Production Well Logging .............. . . 10 


\section{INTRODUCTION}

The testing of a geothermal resource involves four significant sequentially scheduled stages. The tests and data of each stage combine to give progressively more definitive information so that each subsequent stage of the geothermal resource development can be implemented with a high degree of confidence.

The tests of each stage also may present data and results that suggest alternatives for proceeding to the next stage. In this plan alternative actions at different stages based on changes in the anticipated resource characteristics will be discussed. However, it is impossible to anticipate all alternative actions available, because of the combined well bore/reservoir/resource character interactions which offer a large number of choices.

The four stages of geothermal resource testing are:

- Tests and data gathering while drilling the production well;

- Initial short term production testing of the production well;

- Tests and data gathering while drilling the injection we11;

- Full scale production testing of both production and injection wells (production to injection response).

Assuming the resource is as anticipated at the selected Holly Sugar bottom hole location, the schedule of testing and data evaluation is as shown in Figure $?$. 
(Weoks after spud and conductor pipe set)

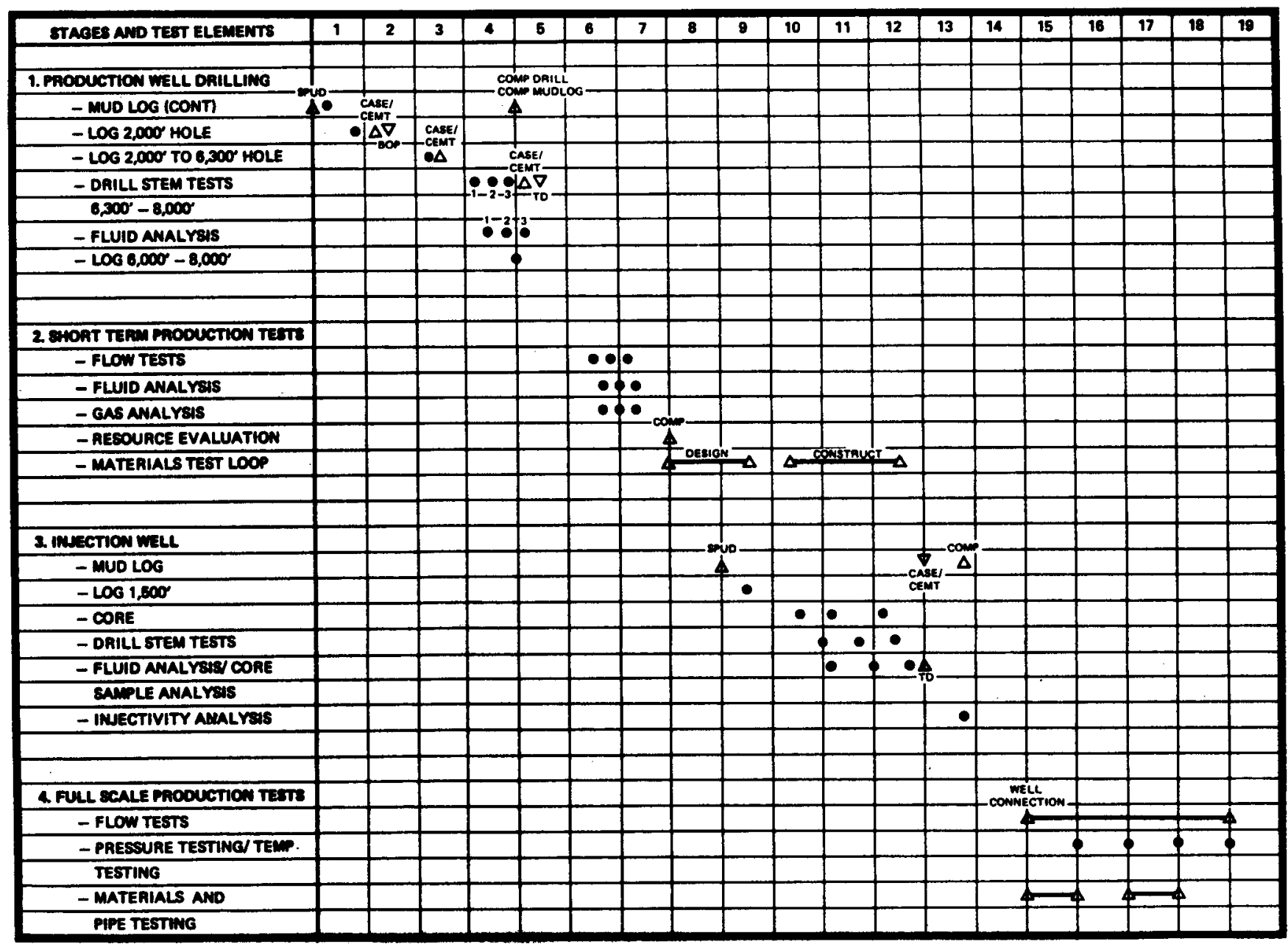

Figure 1. Schedule and Milestones for Resource and Injection Testing, Holly Sugar Project 


\section{RESOURCE TESTING AND DATA GATHERING}

\subsection{PRODUCTION WELL DRILLING}

\subsubsection{Mud Logging}

Mud logging for this particular well includes monitoring the following:

- Mud temperature (drilling fluid)

- $\mathrm{CO}_{2}$ from the flowline

- $\mathrm{H}_{2} \mathrm{~S}$ fromt he flowline

- Hydrocarbon gas analysis

- Rock bulk density

- Detailed lithologic log

- Drili rate (penetration rate)

- Mud pit level monitoring

- Mud physical characteristics

- Annulus flow rate

- Returns log time (time for cuttings to arrive at the shale-shaker from the bottom of the hole)

Each of the above provides the well-site geologist/engineer with real time empirical data for making reasonable decisions regarding drilling a "good" hole as well as providing data for performing significant down-hole tests over the proper lithological interval.

Mud temperature in and put of the hole provides empirical data indicating whether or not the bore hole is heating up. Differential mud temperature in conjunction with log time estimates, penetration rate and logged cuttings analysis can provide strong indications of the kinds of thermal activities that may be taking place in the well bore. In addition, mud differentials (in and out temperatures) can be used in conjunction with temperature logs to assist in determining just where in the lithologic section thermal events may be taking place. Being empirical, mud temperatures by themselves will not provide data that can be used to determine thermal conductivity, 
diffusivity, capacity or specific heat values. However, the mud temperature log may offer clues of where these characteristics may change. Also, mud temperature monitoring will provide a safety factor to prevent destruction of down hole tools, bits and measuring devices. Measuring mud temperatures may also result in changing the type and consistency of cement used for setting casing.

$\mathrm{CO}_{2}$ in significant quantities can alter the desirable characteristics of drilling fluids. This is the prime reason for monitoring the $\mathrm{CO}_{2}$ content. However, it can also be used as an indicator when penetrating a porous rock section which probably contains acid fluids. In borehole sections with geothermal production potential, the existance of $\mathrm{CO}_{2}$ may assist in selecting specific test zones.

$\underline{H}_{2}$ S monitoring, aside from the safety factor, may be useful in selecting potential production zones. However, its prime value is in materials selection and in making an early determination if $\mathrm{H}_{2} \mathrm{~S}$ abatement measures must be taken if the well turns out to be productive.

Hydrocarbon gas content is required by the California Division of $0 i 1$ and Gas. Data indicating hydrocarbons may be useful in selecting zones of porosity in the section, but in general will not provide significant geothermal test information.

Rock bulk density helps in determining mud pump pressures and stroke rates so that cuttings are brought to the surface and the hole is "kept clean". However, this data, in conjunction with lithologic logs and rates of penetration data, can greatly aid in selecting packer seats for drill stem testing.

A detailed lithologic log, when correlated with electric and other geophysical logs, is valuable in obtaining and verifying porosity, permeability, and calculating potential productivity of specific zones. This is one of the most valuable pieces of data obtained by mud logging, relative to potential well productivity. 
Monitoring the foot to foot drill rate accomplishes two fundamental tasks. It provides an instantaneous record of the depth being drilled and provides a record of the penetration rate of particular formations. Many times a significant change in drilling rate identifies the boundary of a new formation, bed or horizon.

Mud pit level monitoring is performed primarily to determine if the well bore is accepting fluids (fluid flowing into the rock formations) or making fluids (formation fluids flowing into the well bore). Fluid level changes may indicate zones of high permeability. However, care must be used in attributing the fluid level change to the zone being penetrated. In some cases the level change occurs in zones "up the hole" or because of changes in mud weight or mud additives that change wall cake character.

Mud physical characteristics (weight, viscosity, rheology and colloid content) must be monitored to prevent formation break-down due to overweight mud, provide sufficient buoyancy to 1 ift cuttings out of the hole, provide wall cake for maintenance of well bore integrity and to prevent separation of chemical components.

Annulus fluid flow rate or the up-date velocity of drilling fluids, while important to keep the mud properly conditioned and the bore hole clean, is not generally useful in defining significant formation character or selecting tests zones. However, the calculated flow, based on mud pumping capacity and stroke rate, is used to determine cuttings $\log$ time. That is the time it takes for drilling chips to arrive at the surface.

The returns log time can be determined in several ways. Calculations based on annulus fluid flow rate and mud pump parameters give a fair estimate. However, the best method is to add some kind of tracer to the inflow mud line. Log time is important in determining the lithologic section and making up the sample (detailed lithologic) log. Without providing for sample log time the prepared lithologic log could be several tens of feet in error depending on penetration rate. Many times the sample log, in conjunction with geolograph 
data, is used to select zones to be tested and choose packer seats.

The test results and data gathered by the mud logging unit will be used throughout the test and production history of the well. It is one of the more useful pieces of well data and is very valuable to future reservoir engineering and development of the resource area.

A sample of mud logging output was furnished by the R. F. Smith Corporation and is shown in Figure 2 . 


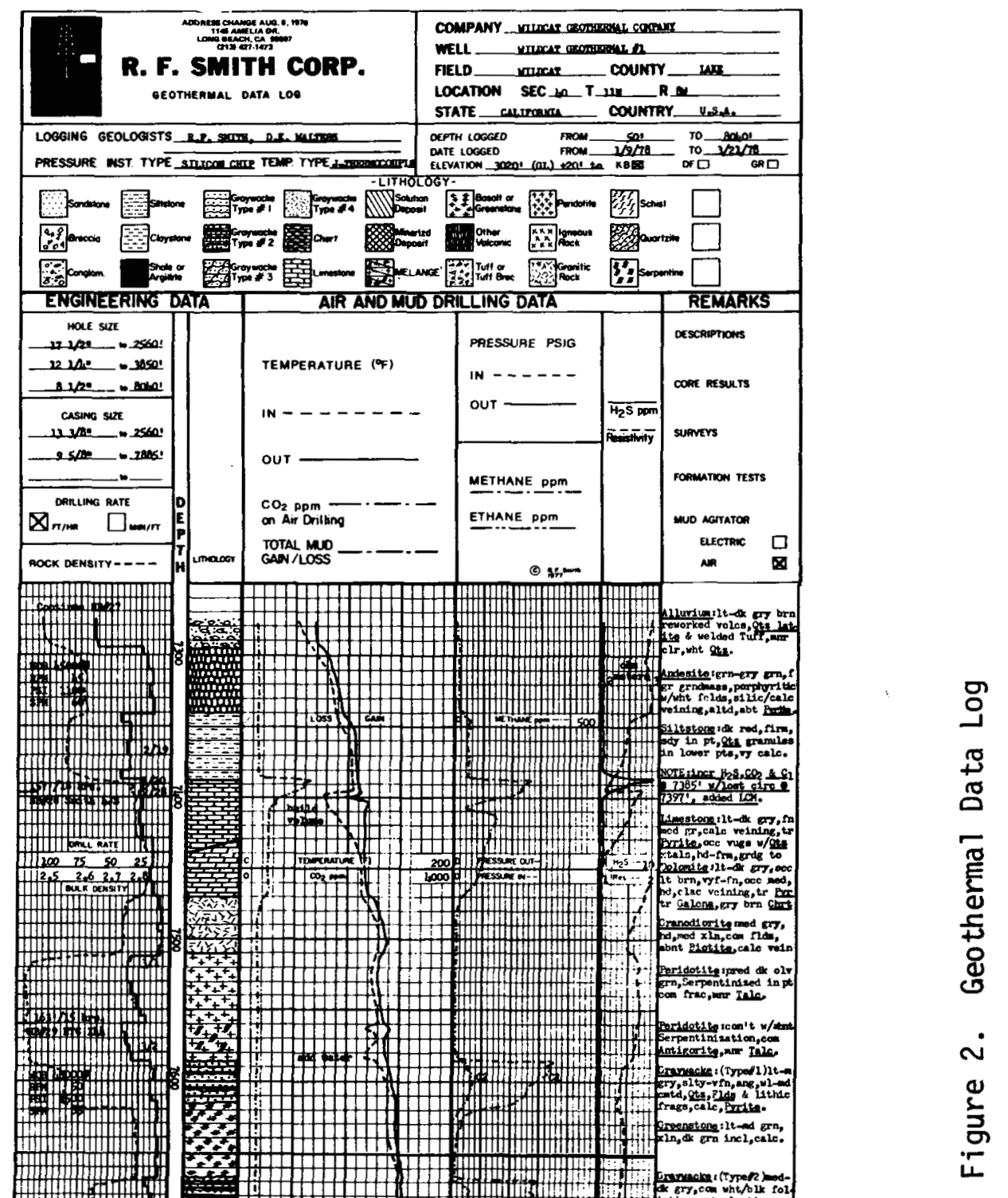




\subsubsection{Geophysical Logging}

Geopbysical logging is one of the most important sets of data gathered in connection with well testing and reservoir analysis. These logs provide information and physical data on porosity, permeability, water content, shaliness (sand/shale ratios), formation salinity, temperature and several other technical parameters necessary for well to well correlations, reservoir engineering, geologic structure, and geophysical analysis.

As part of the overall resource testing program for the project, open hole logs will be obtained from three separate intervals. The first set of logs will be obtained after drilling 2000 feet of the production well hole. This section is for setting surface pipe (casing) to protect near surface aquifers and to prevent down hole fluids from uncontrollably reaching the surface or entering the up-hole water zone. In this particular zone or interval the primary information sought relates to the bed-boundary locations and the shape and size of the hole. However, the lower 500 feet of the section may be valuable for estimating fluid acceptance of the injection well and estimating the volume of injection horizons. To provide the desired data a dual induction laterlog and a four arm caliper log will be run. These logs will provide correlation data and be used to calculate the amount of cement needed for setting surface casing.

A more complete set of logs will be necessary for the next drilled section (4300' of hole-from 2000 feet to 6300 feet measured depth (MD)). The logs run in this section will provide data for future correlation between the production well and the injection well. It will also provide necessary reservoir engineering data to determine fluid acceptance in the injection well. These logs will provide fundamental data on the geothermal and geologic character of the penetrated section. The logging program for providing information will be composed of 1) a dual induction laterlog, 2) a formation density compensated $\log , 3$ ) a gamma ray $\log , 4)$ a compensated neutron $\log , 5$ ) a borehole compensated sonic $\log , 6$ ) a salinity coriband 
7) a four arm caliper $\log$ and 8) a high resolution temperature $\log$. The basic information provided by each $\mathrm{log}$, the information developed by that $\log$, the log data combinations and the information developed through these log combinations is shown in Table 1. Overall lithologic trends, thermal gradient patterns and bed geometries will be used to determine geologic structure at depth and locate fault and fracture systems. The thermal gradiant pattern in this interval will be used to better estimate temperature at depth.

The third set of logs will be the same suite as that used in the previous interval. However, in this section (6300 feet to 8000 feet) the primary purpose of logging will be to locate fracture zones with significant geothermal potential. A11 downhole logs from 2000 feet to total depth (TD) will be recorded on tape for later computer processing if this becomes desirable. (Note that a salinity coriband requires computer processing) In this third section, $\mathrm{CO}_{2}$ and other noncondensible gases may be encountered. Zones containing these gases may be evident in the bulk density log or identified by densityneutron cross plots. Blanking off these zones, if it does not affect production, may be worthwhile because of better fluid chemistry.

If the quality, continuity, and/or adhesion of cement in any portion of the production well is suspect, it may be necessary to run cement bond logs and/or thickness logs. Void spaces between the cement and rock formations in geothermal wells may result in collapsed casing.

\subsubsection{Alternatives in the Logging Program}

An alternative to running the logging program as planned (i.e., in three intervals from $0-2000^{\prime}, 2000^{\prime}$ to $6300^{\prime}$ to a Total Depth (TD) of $8000^{\prime}$ ) would be to run more intervals if a significant production zone is indicated from the drilling data. Production zones requiring additional logging would be most likely to occur at the greater depths, $\left(6300^{\prime}\right.$ to $\left.8000^{\prime}\right)$ but may occur elsewhere in the section. 
Table 1. Production Well Logging

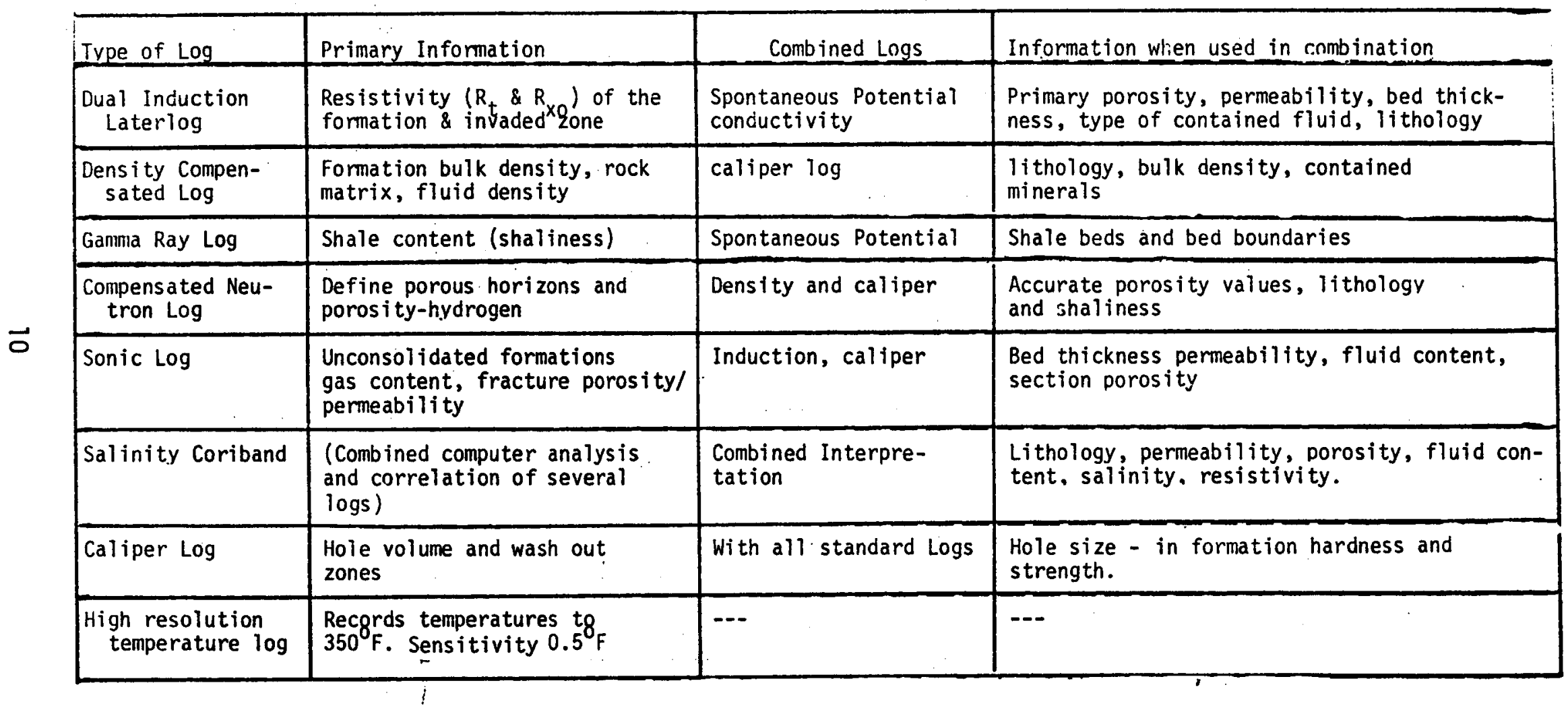


An alternative to running directional shot and caliper logs for hole deviation corrections and true depth calibrations would be to run a dipmeter. However, this alternative is costly and not anticipated at present.

A teflon line rather than a standard cable may be necessary in the third logging interval (6300' to $8000^{\prime}$ ) because of high temperatures. The decision to use teflon line will be made based on the temperatures of the drilling fluids in the return lines and the temperature gradient data obtained in the earlier log runs.

\subsubsection{Logging Program for the Injection We11}

The logging program for the injection well will be similar to that for the projection well.

Two open hole logging intervals will be required, one from 0-1500' the other from $2000^{\prime}$ to $6000^{\prime}$. The first suite of geophysical logs to be run will include a dual induction laterolog and a four arm caliper log. Logs for the second interval will include a dual induction laterolog, a formation density compensated $10 \mathrm{~g}$, a gamma ray $\mathrm{log}$, a compensated neutron $\log$, a bore hole compensated sonic log, a salinity coriband and a 4-arm caliper.

An option to run a dipmeter in place of the four arm caliper will be kept. The primary information sought from the first interval is bed boundary locations and shape and size of the borehole. The primary information sought from the second interval (1500' to 6000') is location of injection horizons and determination of the amount and type of fluid acceptance. Log type selection rationale has been stated previous $1 y$.

Cased hole logs such as the cement bond logs and the electromagnetic thickness tool logs may be used in case of suspected poor cementing jobs.

Problems may occur while drilling that would necessitate additional casing logs being run. No attempt is made here to anticipate the situations and logs necessary for problem evaluation. 


\subsubsection{Drill Stem Testing}

Drill stem tests (DST's) will be run to evaluate the Holly Sugar well's economic prospects under dynamic rather than static conditions at a time early enough to decide to continue the drilling effort.

Prior to drill stem testing (DST), the hole and drilling fluid will be conditioned as necessary to prevent sloughing and to minimize the potential for "stuck" packers. All safety proceedures required by state, local, or federal agencies, for example, compliance testing of blow out preventers will be met. Hydrostatic pressure will be balanced with the proper weighted drilling fluid to prevent formation breakdown and provide for good fluid flow from the tested formations. Fluids recovered from the DST's will be directed to Baker tanks for haulage to special dump areas, if necessary.

\subsubsection{Production Well Tests}

DST's are not planned for the upper 6300 feet of hole. It is not anticipated that proper temperatures or productivity will be encountered prior to this depth. However, the option of running DST's on unexpected production potential will be retained.

The first tests will be run based on mud temperature differential, lithology encountered and possibly signs of increased mud volume. The plan is to drill through the first sand or fracture permeability series encountered below 6300 feet. A casing type packer will be placed near the bottom of the casing, along with the instrument package, and the hole below the casing opened for testing. After this initial test, DST's will be conducted on the basis of dynamic well and mud conditions as defined by the mud log, geolograph and sample analyses. Tandem packers and double instrument packages will be run in all cases. The immediate circumstance will dictate the types of packers, "hook-wal1" or stem assembly.

The DST assembly will be equipped with two valves, two pressure recorders, two clocks, two high temperature recorders, and two recording plates (brass). The full set of redundant equipment is to 
ensure data retrieval and to provide a measure of back-up in case of recording equipment failure.

By recording changes during successive flow and shut-in periods, an evaluation of fluid, flowrate, flow pressure and shut-in pressure responses will be possible for the tested zone. Fluid samples will be obtained from the last flow period, if the formation flows or from the lower pipe stands if the zone does not flow.

The use of strattle packers for DST's based on log runs after reaching TD was evaluated. With strattle packers, any section of the hole could be isolated and evaluated. However, in the Imperial Valley, there are several disadvantages, such as the high probability of losing tools, equipment failure (no packer seat in the sedimentary section) or getting equipment stuck. Strattle packers will be run only if the circumstances dictate the necessity.

\subsubsection{Injection Well DST}

Drill stem tests will also be run for the interval from 1500' to $6000^{\prime}$ in the injection well during drilling. The procedure will be the same as for the production we 11 and has been described above. The data will be used in conjunction with geophysical logs to determine formation acceptability, establish which zones should be opened to accept injected fluids, to define the casing program and to size the injection pump(s).

The following surface measurements are to be taken when DST flow reaches surface:
a. Salinity of water $\left(\mathrm{ppm} \mathrm{Cl}^{-}\right)$
b. Temperature of water $\left({ }^{\circ} \mathrm{F}\right)$
c. Ph of water
d. Flow rates and pressures measured through a Test Separator, (adjust bean size as required)
e. Density of water (1bs/gal)
f. $\mathrm{CO}_{2}$ content of water
g. Monitor for $\mathrm{H}_{2} \mathrm{~S}$ content 
h. Flow samples every 5 minutes for the first 30 minutes of final flow and every 15 minutes thereafter

i. Conductivity of water

j. A minimum of 3 gas samples for chromatographic analysis.

Backscuttle clean, sampling backscuttled fluid until mud reaches surface and P.O.H. Test string to include one bar type backscuttle valve and one pressure type. String to include safety joint, bumper subs, and other equipment bottom to top as follows:

1. Special Surface Valve with $2 \frac{1}{2}$ in. I.D., $20 \mathrm{ft}$. of 3 in. 15,000 psi Chieksan hose and 3 in. flange on top of head for wireline lubrication.

2. Drill Pipe

3. Pump Out Reverse Sub

4. Drill Collars

5. Handling Sub

6. MCIP Hydrospring with Sampler (Down hole sampler).

7. Extension Joint

8. 2 - A.P. B.T. Pressure Recorders

9. Big John Jars

10. V. Safety Joint

11. R.T.T.S. Packer Body

12. Anchor Pipe Safety Joint

13. 35: Flush Joint Anchor Pipe

14. 3 - B. T. Recorder.

2 - Temperature

1 - Pressure

\subsubsection{Fluid Analys is}

The drill stem test equipment provides for obtaining a pressurized fluid sample while the DST's are being run as shown in the description of the test string. 
This system in conjunction with obtaining a series of "grab" samples from the pipes as the DST equipment is being recovered, will provide vital fluid chemistry data. The formation sampler (item 6 above) will be shipped to a laboratory for analysis. This analysis will provide data on gas content, fluid chemistry, and enthalpy determination that may not be available from "grab" samples. Comparison of results from the two sample methods will be of value in determining scale types and temperature values at which scale types begin to precipitate. In addition to providing much needed data for materials selection for the plant system, the sample analysis will provide information concerning resource temperature and possibly age. This initial data on the fluid physical characteristics and chemistry, while vital, does not represent a total fluid test and analysis program. Additional fluid testing will be required during the short term production tests and during full scale production tests.

The results of the chemical analysis of the captured fluids will greatly assist in deciding the next step in the development program and in determining available options.

\subsection{SHORT TERM PRODUCTION TESTING}

The short term production tests will only be initiated if previous DST testing, geophysical log analysis and mud log interpretation indicate a potential resource. If no possible resource is encountered then other options will be considered at this point in the project. These might include:

- Drilling deeper

- Moving the rig westward to an untested fault block

- Setting a "whipstock" up the hole and directionally drilling into a different fault block

- Attempting a "hydrofrac" to fracture into nearby faults and fractures

- Abandonment of the project.

Short term production tests consist of flowing the well through the blow-down line to a set of (probably two) Baker tanks while the 
rig is still "on the hole". If each Baker tank will hold 10,000 gallons of fluid and the well flow rate is 1,000 gallons per minute, then the maximum full flow time will be 10 minutes. Therefore, the flow rate will be "choked" at the blow-down line. Estimates of the reservoir capacity will be made from this "choked" rate. Continuous recording of flow rate (approximately $200 \mathrm{gal} / \mathrm{min}$ ), wellhead pressure, and wellhead temperature will be accomplished. Samples of the fluid at the well head will be taken using pressure vessels designed for obtaining geothermal samples. Samples of the fluid (possibly 2 phase flow) will be acquired using techniques generally approved by Vetter Research Laboratories of Costa Mesa, California. The number and length of short term production tests will depend a great deal on the quality of the resource. If they are marginal, then more tests of longer duration may be required. If an exceptionally "good" resource is tested the decision to proceed rapidly may prevail and testing costs accordingly reduced.

Fluid and gas analysis of collected samples will be completed as soon as practical. The data will be provided to the plant design engineers so that they may proceed with their system design. In addition, the obtained data will be used to evaluate the resource, determine measures necessary to reduce scaling, design a production test materials test 10op, and select an injection pump system.

This intermediate testing of the production well will be of short duration, but is considered to be almost manditory before proceeding with drilling the injection well. 


\subsection{INJECTION WELL}

The injection well testing program will be accomplished in a manner supportive to three objectives:

- to prevent or minimize subsidence

- proper disposal of thermal fluids:

- prevention of contamination of the environment and water resources in the local area.

The drilling : and testing program for the injection well contains the same test elements as those described for the production well. However, the obtained data will be used in a slightly different manner.

\subsubsection{Mud Logging}

The mechanics and measured parameters will be the same for the injection well as those obtained in the production well. However, samples of the cuttings will be more completely described mineralogically, in order to better estimate the chemical compatibility of the injection horizon and the injection fluid. Chemical incompatibility could result in early clogging of the injection well. Knowledge of the formation mineralogy may be used to suggest additives that would make the injected fluids compatible and increase the life cycle of the injection wel1.

\subsubsection{Geophysical Logging}

The logging program for the injection well contains the same elements as those of the production well. The first 1500 feet of hole will be logged using only the dual induction tool and the four arm caliper. These data will provide the necessary information for cementing the surface casing and will provide data for strata correlation with the production well.

Below 1500 feet the same suite of logs will be run as prescribed for the production well in the $2000^{\prime}$ to $6300^{\prime}$ interval. The obtained information will provide data on permeability, porosity, density, shaliness, water content, water salinity, bed thickness, formation temperature, and other data necessary to engineer injection of spent 
fluids. Each of the logs and their purpose was discussed earlier. For the injection well the difference is that the data will be used to determine fluid acceptance rather than productivity.

Log correlation of injection well formations with the production well horizons will aid in determining the volume of the injection reservoir. This data in conjunction with DST information will be used in the injectivity analysis.

\subsubsection{Cores and Core Data}

At present coring is not anticipated. However, if the mineralogy of the injection or proposed injection horizons becomes suspect, in terms of chemical compatibility, it may be necessary to shoot sidewall cores to directly obtain uncontaminated mineral samples. If obtaining core information becomes necessary the obtained samples will be sent to a professional laboratory for analysis.

Conventional coring or side-wall coring is not anticipated, but it will be retained as option or information alternative.

\subsection{FULL SCALE PRODUCTION TESTS}

By far the most significant test series will be full scale testing. This testing will require:

- Installation of the wellhead equipment at the production well

- Installation of the materials test loop

- Installation of the injection system, including pump(s)

- Installation of the production and injection well surge tanks.

In order to reach this stage of the testing program all previous stages must have presented positive results. Therefore, alternative actions are very limited. It may be possible to reduce the length of testing, eliminate the planned materials test loop, and eliminate that portion of the materials test loop that provides for injections of chemical additives to the produced fluids. However, the reduction or elimination of any of these subsystems could result in serious down-stream problems. 


\subsubsection{Installation of Equipment}

Well head equipment, test instrumentation, surge tank, and the chemical additive system were discussed in some detail in a previous report to DOE (Drilling and Resource Development Plan, June 1979 TRW No. 97248.000). The final well head system design is shown in Figure 3 of this report.

The final design of the production well surge tank and chemical additive system will occur as part of The Short Term Production Tests (Section 2.2) previously discussed. This design will also include selection of the injection pump, design of the injection surge tank and chemical additive system. Two chemical additive systems are suggested as appropriate; one at the production well for fluid treatment prior to entry into the plant system (additives at this point will be concerned with scaling and precipitation of solids), and the other at the injection well for fluid treatment prior to subsurface injection (additives may be required to make the produced fluid compatible with the mineral and fluid content of the injection horizons). The concept design of these subsystems was presented at a design review meeting in January (ETEC Technical Review) and will be finalized as part of The Short Term Production Tests (Figure 1).

\subsubsection{Flow Tests}

Although testing is discussed separately in this report, all the following tests will be conducted in parallel and constitute a test of the total production capability.

Dr. V.0. Vetter has discussed the problems with measuring mass/ heat flow and determining accurate fluid enthalpy values at the we17head. The main problem is associated with the physical installation of measurement devices. Their installation upsets the physical flow and may cause changes affecting the mass flow calculations. However, the information required to continue with conversion of the Holly Plant to geothermal energy does not require the same sensitivity as measurements that must meet ASTM standards. Considering these $1 \mathrm{imi-}$ tations, a flow meter, temperature gage and pressure gage will be 


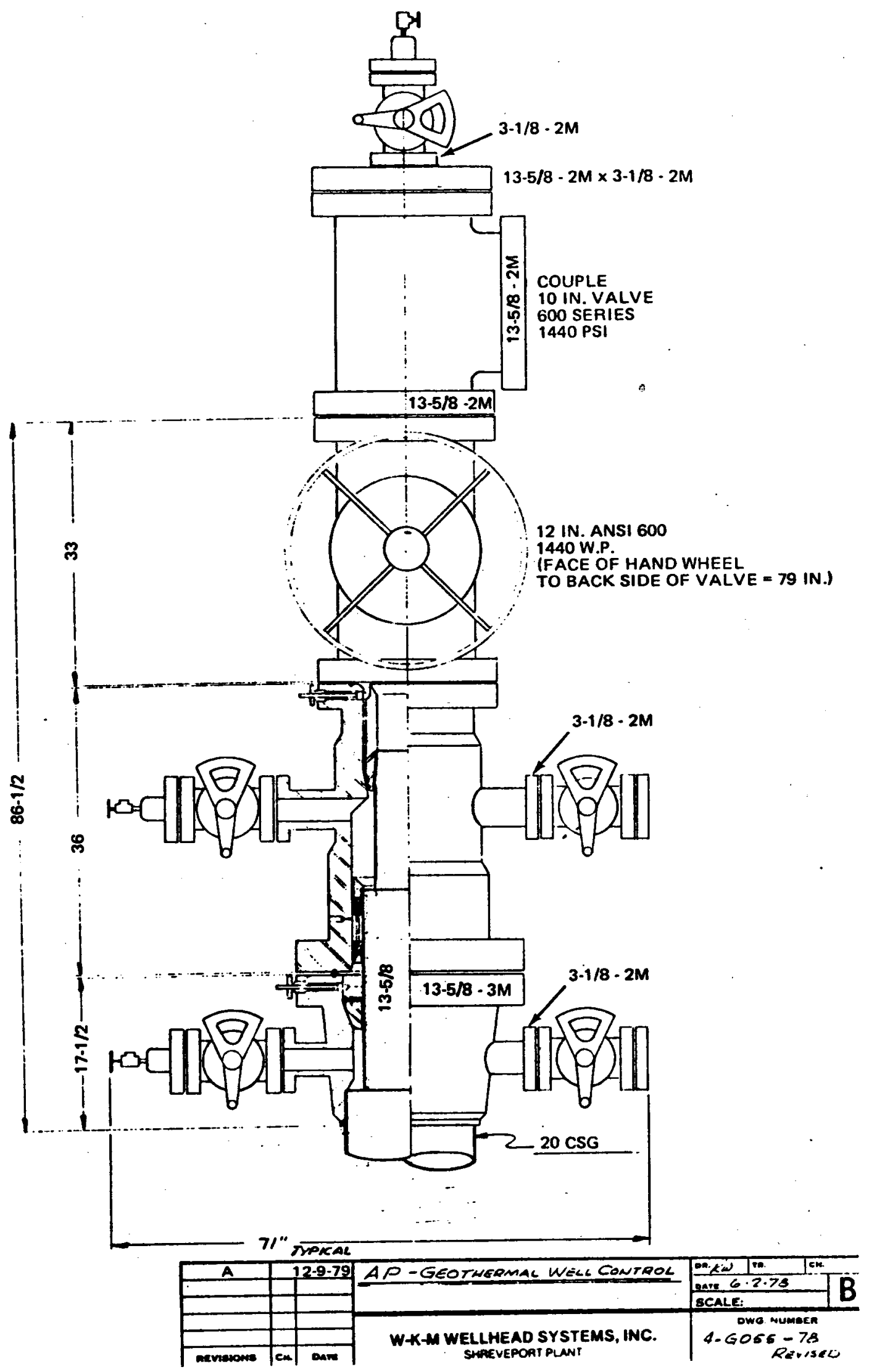

Figure 3. Wellhead Design 
installed at the wellhead prior to fluid entry into the surge tank. The particular types and models will be part of the test loop design and cannot be specified until the results of DST and short term tests have been analyzed. In concept the system is as shown in Figure 4.

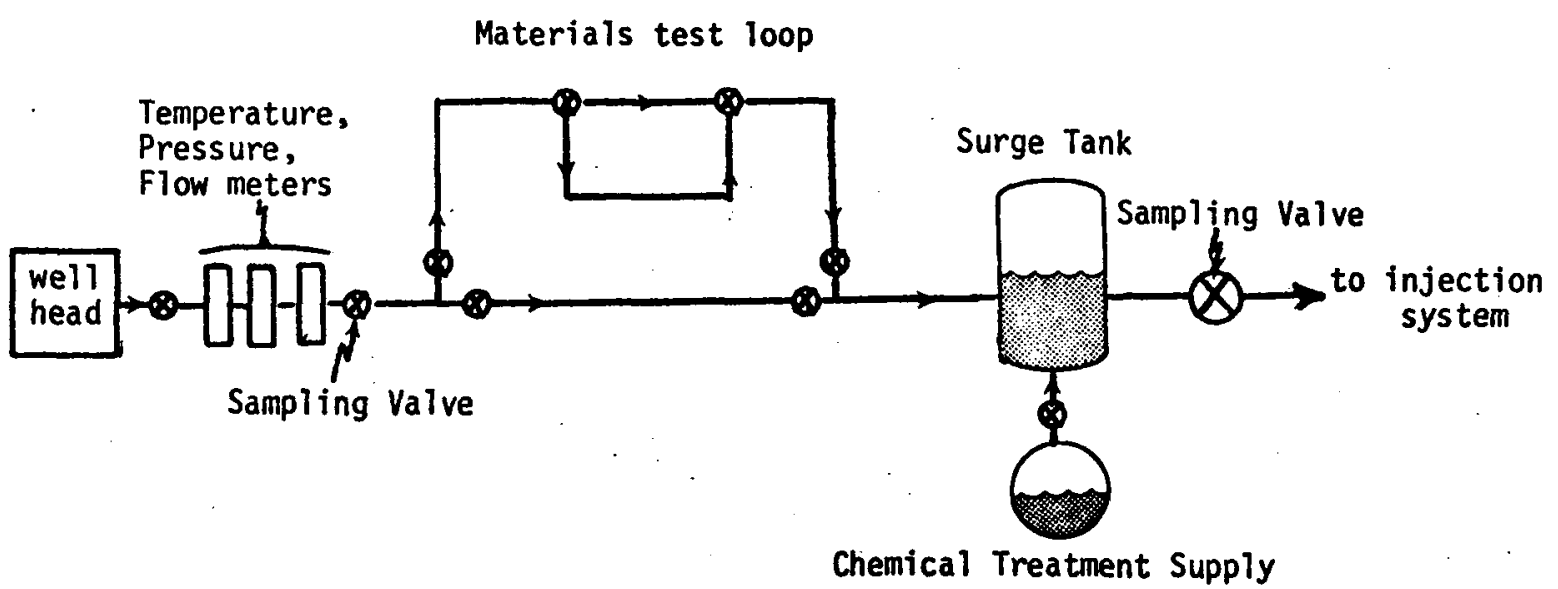

Figure 4. Production Well Test Loop

Production samples of the geothermal fluids will be collected at least twice weekly for detailed chemical and gas analysis. The number of samples gathered for testing and analysis can be increased if changes appear to be taking place. 
Present injection well design includes two Gardner-Denver model QAF-300HP continuous duty positive displacement pumps. This pump system will provide for handling 1528 gallons of fluid per minute at a maximum pressure of 606 psi when $4 \frac{1}{2}$ inch plunger is used. The temperature rating of this system is $370^{\circ} \mathrm{F}$ which should be adequate for injecting the spent fluids. Hardening for handling corrosive geothermal fluids is not anticipated.

The system concept, which will be finalized after the results of DST and short term testing, is shown in Figure 5.

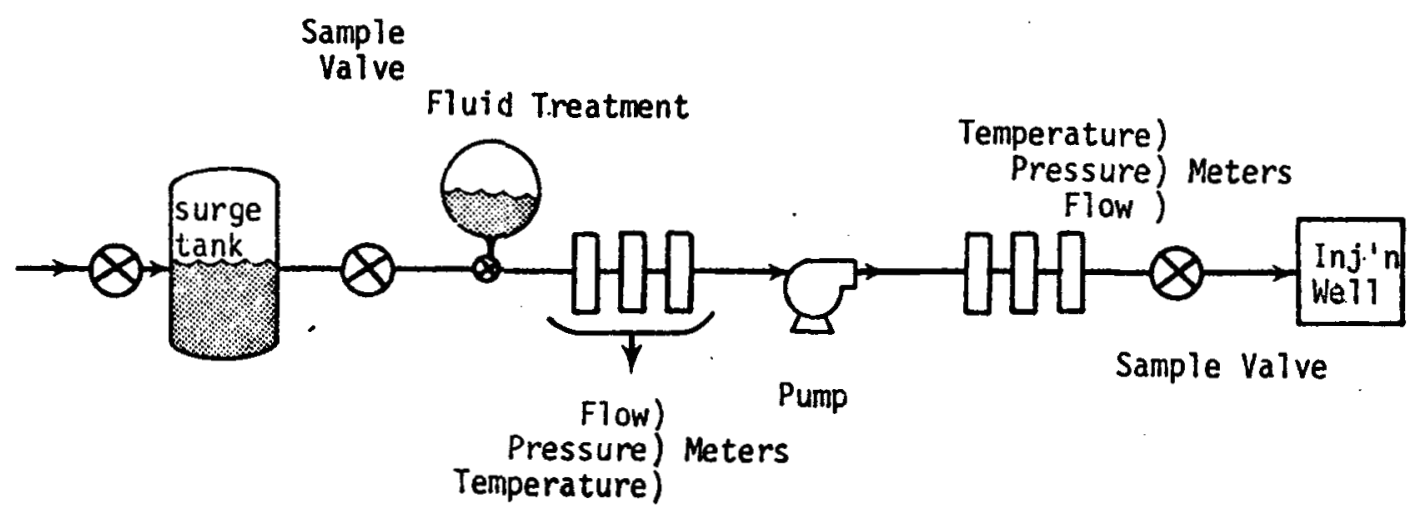

Figure 5. Injection Well System

\subsubsection{Pressure/Temperature Testing}

The pressure and temperature continuity along with the flow rate of the geothermal fluid at the production wellhead over a significant time should reflect reservoir productivity. Measurements of the pressure and monitoring and recording the pressure decrease or the establishment of a stabilized pressure will be necessary prior to the construction 
of the total conversion system. The production test plan calls for four weeks of continuous pressure and temperature monitoring. This should be sufficient to establish reservoir credibility.

The other aspect of pressure and temperature monitoring is concerned with the injection well. Pressure will be closely monitored to determine the potential of injection well clogging. If the back pressure begins to build on the injection pump, analysis of chemical additives vs formation chemistry and the impact of temperature differentials between the formation and the injected fluids will begin immediately.

\subsubsection{Materials and Pipe Testing}

A materials test loop (Figure 4) has been provided for as part of the overall testing program. This loop will be very similar to that used by Phillips Petroleum Company at their Roosevelt, Utah, geothermal field. Their test loop provides for testing scaling rates in different sized pipes as well as coupon testing of materials. Results from this test loop may not provide data in time to alter construction or procurement of long lead time items, but may be of great value in selecting piping to the plant and other subsystem elements that will be directly exposed to the geothermal fluids. 